\title{
The Effect of a Motivational Speaker on Dental Student’ s Performance on National Board Part 1 (NBDE-1)
}

\section{Yasmine M Haddad ${ }^{1}$, Ezinne I Ogbureke ${ }^{2}$, Katherine E Price ${ }^{3}$, Gena D Tribble ${ }^{4}$ and Raymond G Koeppen ${ }^{5}$}

${ }^{1}$ Department of Biomedical and Diagnostic Sciences, The University of Texas School of Dentistry at Houston SOD 5371.7500, Cambridge Street Houston Texas-77054, USA

${ }^{2}$ Department of General Practice and Dental Public Health, The University of Texas School of Dentistry at Houston SOD 5330.7500, Cambridge Street Houston Texas-77054, USA

${ }^{3}$ The University of Texas School of Dentistry at Houston.7500 Cambridge Street Houston Texas-77054, USA

${ }^{4}$ Department of Periodontics and Dental Hygiene BBS-5318, The University of Texas School of Dentistry at Houston.7500 Cambridge Street Houston Texas-77054, USA ${ }^{5}$ Department of Restorative Dentistry. The University of Texas School of Dentistry at Houston SOD 5350.7500 Cambridge Street Houston Texas-77054, USA

"Corresponding author: Ezinne I Ogbureke, Assistant Professor, Department of General Practice and Dental Public Health, The University of Texas School of Dentistry at Houston SOD 5330.7500, Cambridge Street Houston Texas-77054, USA, Tel: +1-713-486-4000; E-mail: ezinne.i.ogbureke@uth.tmc.edu

Rec date: Dec 03, 2015; Acc date: Dec 18, 2015; Pub date: Dec 21, 2015

Copyright: $\odot 2015$ Ogbureke S, et al. This is an open-access article distributed under the terms of the Creative Commons Attribution License, which permits unrestricted use, distribution, and reproduction in any medium, provided the original author and source are credited.

\begin{abstract}
Objectives

The primary purpose of this study was to determine if there is a positive correlation between incorporating a professional motivational speaker in the National Board Dental Exam Part 1 (NBDE-1) preparation course and the students' pass rate on the NBDE-1. The secondary purpose was to determine the effect of the motivational speaker on students' (1) motivation to prepare for the NBDE-1 (2) self-perceived ability to control their own stress on exam day, and (3) perception of the effectiveness of the dental school curriculum and the NBDE-1 review course in preparing them for the NBDE-1.
\end{abstract}

\section{Methods}

The subjects in this study consisted of 99 second year dental students enrolled in the NBDE-1 Review Course during the 2014. Summer Session at the University of XXX. Survey Monkey was utilized to distribute the same survey at three time points.

\section{Results}

Incorporating a professional motivational speaker positively correlated with an increase in the pass rate on NBDE-1 from the following percentages in the past five years: $96 \%, 96 \%, 96 \%, 95 \%$, and $96 \%$ to the following pass rate on NBDE-1 in 2014:99\%. A participation rate of at least $60 \%$ was achieved for all three surveys. Results also indicated a positive correlation between the utilization of a professional motivational speaker and students' motivation, perceived ability to control their stress, and perception of preparedness for NBDE-1.

\section{Conclusion}

Although the NBDE-1 pass rate in 2014 increased compared to the past five years, a larger sample size is needed for statistical significance.

Keywords: Motivational speaker; National board of dental examination; Dental student's performance

\section{Introduction}

In psychology, motivation is a force that energizes and directs behavior toward a goal [1].

Motivation is divided into two broad categories-Intrinsic, when the force comes from within such as in curiosity or need to excel and Extrinsic when it is driven by outside forces such as the desire to impress others [2]. Various studies have shown positive improvement to student's academic achievement and worker's performance based on the extent to which they are motivated $[3,4]$.

In a study of native Chinese Speakers learning the English language, cultivating student's integrative motivation was cited as a key element in improving outcomes [5]. Extensive research has been done on the effect of motivation on learning a foreign language or particular subjects but currently there is a lack of evidence on the effect of motivation on standardized testing scores. A search of Google, PUBMED, Google Scholar, yielded no results of research specifically targeting the effects of a professional motivational speaker on standardized testing results which is the focus of this study. 
The National Board Part 1 Examination (NBDE 1) is a major test administered to all dental students in the United States in the second year of the 4 year dental education and is part of the fulfillment for eligibility for licensure in various states.

The examination format has undergone several modifications over the years and currently consists of 400 multiple choice questions covering the fields of Anatomic Sciences, Biochemistry-Physiology, Microbiology-Pathology and Dental Anatomy \& Occlusion [6].

There are two broad categories of standardized tests:

1. The Norm referenced tests which tests the ability of the subject in comparison to others within the same group. The most common example is the IQ testing.

2. The Criterion referenced test tests the ability of a patient to answer questions based on an established criterion.

The National Board Dental examinations are criterion referenced tests in which the total scores are converted to a scaled score that ranges from 49-99 and the minimum passing score is 75 .The result as at 2012 is reported to the individuals as pass/fail [6].

\section{Methodology}

The study was approved by the Institutional Review Board (IRB) of the UT Health Sciences Center in Houston Texas which allowed us access to data for the NBDE 1 performance in previous years and also to survey the students.

Three short surveys at specific intervals were electronically distributed using Survey Monkey to a class of 99 dental students consisting of 46 males and 53 females of various ages. The study population included all the second year dental students who are enrolled in the Interdisciplinary Biological Sciences Review Course that was offered in the Summer Session of 2014. The course was held from June 2 nd to June 30th and consisted of 4 hours of classroom time, 8 hours of practice tests, and $20 \mathrm{hrs}$ of protected study time.

\section{Inclusion criteria}

Being a second year dental student at the UT-School of Dentistry at Houston who is taking the interdisciplinary Biological Sciences Review Course that is offered in the summer session of 2014. Exclusion criteria: Not being a second year dental student at the UT-School of Dentistry at Houston who is taking the Interdisciplinary Biological Sciences Review Course that is offered in the summer session of 2014. The first survey was administered at the very initial class on June 2nd. The second survey was administered at the conclusion of that first class, after a professional motivational speaker addressed the group. The last survey was administered at the end of the course on June 30th, after the same speaker presented for a second time, just weeks before the NBDE-1 Examination.

The four-question survey was meant to assess:

(1) The stress level, (2) the motivation, and (3) the self-perceived preparedness of students studying for the NBDE Part I.

Question\#1- I feel highly motivated to prepare well for NBDE Part 1. Question \#2- I feel that I can successfully control my stress on the NBDE Part 1 exam day Question \#3- I feel that the first two years curriculum prepared me very well for NBDE Part 1
Question \#4- I feel that the resources available in the current course, Interdisciplinary Biological Sciences Review, prepared me well for the examination.

There were three possible responses to each survey question, and each response was assigned a weight for use in statistical calculations: 1 point $=\mathrm{I}$ agree; 2 points $=\mathrm{I}$ feel neutral; 3 points=I disagree. Therefore, lower values corresponded to a higher level of agreement with each survey question. Mean, median, and standard deviation were then calculated for each question.

There was no direct interaction with the participants for the purposes of the study and students only received the survey questions via email.

\section{Results}

There were two main goals in this study. The first goal was to determine the effect of a professional motivation speaker on the dental class' feelings of motivation and preparedness prior to taking NDBE1. The second goal was to determine if incorporation of the motivational speaker positively correlated with a higher exam pass rate when compared to previous years when no motivational speaker was used.

\section{Goal 1: Effect of motivational speaker on feelings of motivation and preparedness}

In order to assess the results for this first goal, three surveys were given to the dental class at three different time points (as described in the Methods section). As each survey period concluded, the results were tallied and general statistics were recorded with the use of Survey Monkey's analytical capability. The results can be observed in Table 1. The questions are listed by column, and the percentage of the dental class that selected each survey answer choice is listed in Table 1. For example, in the Pre Speaker Survey, for the first question ("I feel highly motivated to prepare well for NBDE Part 1"), 49.2 percent of survey respondents answered "I agree," 36.1 percent answered "I feel neutral," and 14.8 percent answered "I disagree."

\begin{tabular}{|c|c|c|c|c|}
\hline & Q1 & Q2 & Q3 & Q4 \\
\hline \multicolumn{5}{|c|}{ 1-Pre Speaker Survey } \\
\hline I agree & 49.2 & 67.2 & 42.6 & 31.1 \\
\hline I feel neutral & 36.1 & 21.3 & 44.3 & 65.6 \\
\hline I disagree & 14.8 & 11.5 & 13.1 & 3.3 \\
\hline \multicolumn{5}{|c|}{ 2-Post Speaker Survey } \\
\hline I agree & 77.8 & 66.7 & 60.3 & 65.1 \\
\hline I feel neutral & 19 & 25.4 & 34.9 & 33.3 \\
\hline I disagree & 1.6 & 7.9 & 4.8 & 1.6 \\
\hline \multicolumn{5}{|c|}{ 3-Final Survey } \\
\hline I agree & 72.6 & 62.9 & 56.5 & 71 \\
\hline I feel neutral & 24.2 & 35.5 & 37.1 & 25.8 \\
\hline I disagree & 3.2 & 1.6 & 6.5 & 3.2 \\
\hline
\end{tabular}

Table 1: Survey Results. 
Citation: Haddad YM, Ogbureke EI, Price KE, Tribble GD, Koeppen RG (2015) The Effect of a Motivational Speaker on Dental Student's

Page 3 of 4

In order to more easily analyze and compare the results of the survey at the three survey points, another set of statistics were used, recorded in Table 2. These calculations were made by assigning a numeric value to each survey answer choice: 1 point=I agree; 2 points $=\mathrm{I}$ feel neutral; 3 points $=\mathrm{I}$ disagree. Then, a weighted average was calculated for each survey question. For example, for the Pre Speaker Survey, Question 1:

Weighted average $=(49.2 \% \quad \mathrm{x} \quad 1)+(36.1 \% \quad \mathrm{x} \quad 2)+(14.8 \% \quad \mathrm{x}$ 3) $=165.57 \%=1.6557$.

The median and standard deviation were calculated and are reported in Table 2 . Thus, more agreement with a survey question can be seen by lower mean values. By reducing the results of each survey question to one number, the comparison between survey questions along the three time points was more straight forward.

Participation in each survey was high, $62 \%, 63 \%$, and $61 \%$ for each respective survey, in a class of 100 students.

\begin{tabular}{|c|c|c|c|c|}
\hline & Q1 & Q2 & Q3 & Q4 \\
\hline \multicolumn{5}{|c|}{ 1-Pre Speaker Survey } \\
\hline Mean & 1.6557 & 1.4426 & 1.7049 & 1.7213 \\
\hline Median & 2 & 1 & 2 & 2 \\
\hline Std.Deviation & 0.72767 & 0.69581 & 0.69148 & 0.52061 \\
\hline \multicolumn{5}{|c|}{ 2-Post Speaker Survey } \\
\hline Mean & 1.2258 & 1.4127 & 1.4444 & 1.3651 \\
\hline Median & 1 & 1 & 1 & 1 \\
\hline Std.Deviation & 0.45877 & 0.63842 & 0.58964 & 0.51749 \\
\hline \multicolumn{5}{|l|}{ 3-Final Survey } \\
\hline Mean & 1.3065 & 1.3871 & 1.5 & 1.3226 \\
\hline Median & 1 & 1 & 1 & 1 \\
\hline Std.Deviation & 0.53066 & 0.52338 & 0.62068 & 0.53636 \\
\hline
\end{tabular}

Table 2: Statistical Analysis of Survey Results.

\section{Goal 2: Motivational speaker correlation with higher exam pass rate}

In order to determine if the incorporation of a motivational speaker correlated with a higher exam pass rate than previous years, an additional statistical analysis was required. The pass rate of the current dental class was compared with the pass rate of the previous 5 years combined. Table 3 shows the current pass rate of $98.99 \%$ compared with the previous combined pass rate of $96.05 \%$.

A Pearson's chi-square test was then used to analyze this data, using 1 degree of freedom. The chi-square value was calculated to be 2.1105 and the $\mathrm{p}$-value was calculated to be 0.2158 .

\begin{tabular}{|l|l|l|}
\hline & $\begin{array}{l}\text { Current Class } \\
\text { (Class of 2016) }\end{array}$ & $\begin{array}{l}\text { Previous Classes } \\
\text { (Classes of 2011-2015) }\end{array}$ \\
\hline Number Passing & 98 & 389 \\
\hline$\%$ Passing & 98.99 & 96.05 \\
\hline
\end{tabular}

\begin{tabular}{|l|l|l|}
\hline Number Failing & 1 & 16 \\
\hline \% Failing & 1.01 & 3.95 \\
\hline
\end{tabular}

Table 3: Pass/Fail Rate of Current and Previous Classes.

\section{Discussion}

\section{Goal 1: Effect of motivational speaker on feelings of motivation and preparedness}

Viewed graphically, Figure 1 shows the mean values from Table 2 using a bar graph format. The results of each survey are shown in different colors, and the survey results are grouped by question. Again, lower mean values correspond to a higher level of agreement with each survey question.

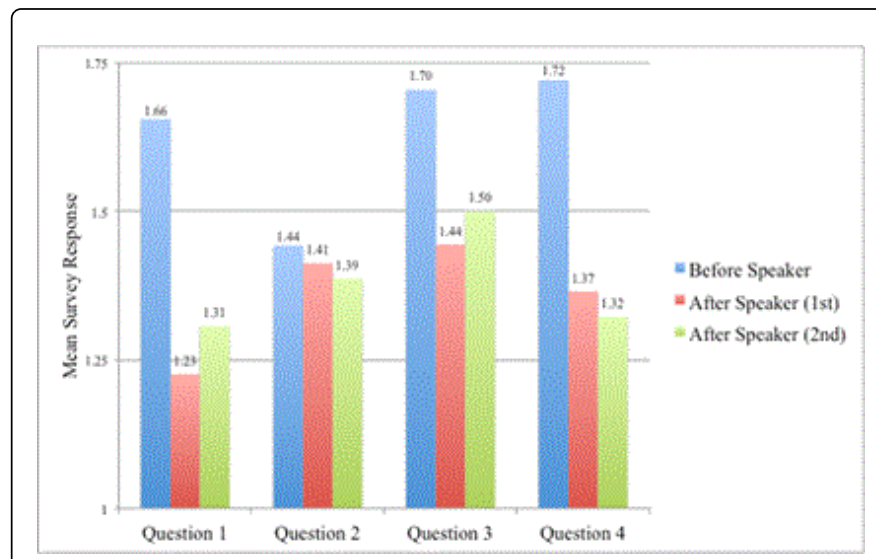

Figure 1: Mean Survey Response Values for Questions 1-4.

Question \#1: I feel highly motivated to prepare well for NBDE Part 1. In reviewing the survey results, the students' motivation saw a large increase (as indicated by the lower mean value) when comparing the responses before the motivational speaker presentation (1.66) with the responses after the speaker (1.23). By the third survey, the motivation seemed to decrease a bit compared to the second survey, but remained much higher than indicated with the first survey.

Question \#2: I feel that I can successfully control my stress on the real NBDE Part 1 exam day. As observed in Figure 1, students reported a small but steady increase in agreement with this survey question along the three time points. This indicated that the students felt they could better control their stress on exam day after hearing from the motivational speaker.

Question \#3: I feel that the first two years curriculum prepared me very well for NBDE Part 1 . For this survey question, there was a large increase in agreement between the first and second survey (1.44 compared with 1.70). The students felt that they were better prepared after the motivational speaker addressed the class. Again, there was a small change in student opinion in the last survey, and the students felt slightly less prepared than in the second survey, but still felt much more prepared when compared with the first survey.

Question \#4: I feel that the resources available in the current course, Interdisciplinary Biological Sciences Review prepared me very well for NBDE Part 1. For this last survey question, again, there was a large 
Citation: Haddad YM, Ogbureke El, Price KE, Tribble GD, Koeppen RG (2015) The Effect of a Motivational Speaker on Dental Student's Performance on National Board Part 1 (NBDE-1). J Health Edu Res Dev 3: 146. doi:10.4172/2380-5439.1000146

Page 4 of 4

increase in agreement after the first motivational speaker presentation. The students felt more strongly that the review course prepared them well for the exam after they initially heard from the motivational speaker. In the third survey, this trend continued, and the students were slightly more in agreement with the survey question when compared with the second survey.

Overall, the survey responses showed a generally positive correlation between incorporation of a professional motivational speaker in the review course and student motivation and perceived preparedness for NBDE-1. Additionally, the impact of the professional motivational speaker was seen to be strongest after the first presentation, suggesting that one presentation by a professional motivational speaker may be adequate to generate the desired impact.

\section{Goal 2: Motivational speaker correlation with higher exam pass rate}

The chi-square test was performed to compare the pass rate of the 2016 class with the pass rate of the previous several years in order to determine if the difference in pass rate percentage was purely by chance. Although the pass rate increased, compared to previous years, $p$ value of the chi square test showed that the increase was not statistically significant.

\section{Limitations}

This study does have several limitations. First, as with any study that relies on a non-required survey to gauge a sample's opinion, the results of this study may be skewed towards the opinions of the students who participated, and may not reflect the opinion of the class as a whole. However, participation was relatively high (above 60\%). Additionally, since this study is in its first year, the sample size was not large enough to detect any statistical significance in exam pass rate with the incorporation of the motivational speaker perhaps a larger sample size would produce a more significant result . Finally, it is difficult in studies of this nature to pinpoint exact causes for changes in survey responses. For example, for Question 2 (I feel that I can successfully control my stress on the real NBDE Part 1 exam day), the increase in agreement with this statement could be attributed to the motivational speaker, or could be attributed to other causes. (Perhaps the decrease from the 2 nd and 3 rd surveys reflects the fact that the students had more time to prepare at the point when the 2 nd survey was administered).
In future studies, perhaps a larger sample size including several other institutions may increase the statistical significance of the result.

\section{Conclusion}

There was a positive correlation between listening to a the motivational speaker and (1) Dental students' motivation to prepare for the NBDE-1 (2) Dental students' self-perceived ability to control their stress on the exam day, and (3) Dental students' perception of the effectiveness of both the Dental School Curriculum and the NBDE-1 review course in preparing them for the NBDE-1.

The impact of the professional motivational speaker on the three above factors was strongest after the first presentation indicating that having the professional motivational speaker presenting once may be adequate to generate the desired impact.

\section{Acknowledgements}

The authors wish to acknowledge the kind assistance of Dr. Stanley Cron in the statistical analysis of the project.

\section{Conflict of Interest}

There are no conflicts of interest to declare.

\section{References}

1. Eggen PD, Kauchak DP (1994) Educational psychology: classroom connections. The United States: Macmillan.

2. Kong Y (2009) A Brief Discussion on Motivation and Ways to Motivate Students in English Language Learning. International Education Studies 2: 2 .

3. Adedeji T (2007) The Impact of Motivation on Student's Academic Achievement and Learning Outcomes in Mathematics among Secondary School Students in Nigeria. Ejmste 3: 149-156.

4. Chintalloo S, Mahadeo JD (2013) Effect of Motivation on Employee's Work Performance at Ireland Blyth Limited. Proceedings of 8th Annual London Business Research Conference, Imperial College, London, UK, 28: 3 .

5. Jin MA (2014) A Case Study of Non-English Major College Student's Motivation in English Language Learning. Open Journal of Modern Linguistics 4: 252-259.

6. NBDE Part I Guide (2014) Joint Commission on National Dental Examinations. 